\title{
EDITORIAL
}

Guaraciaba Michelleti

Universidade de São Paulo, São Paulo, SP, Brasil

Universidade Cruzeiro do Sul, São Paulo, SP, Brasil

Maria Inês Batista Campos

Universidade de São Paulo, São Paulo, SP, Brasil

\section{Discurso, memória e ensino}

Com a temática Discurso, memória e ensino, o presente número congrega artigos que abordam o papel da memória na construção dos mais variados discursos. Nele avultam, entrelaçadas ao discurso e à memória, as questões relacionadas ao ensino, uma preocupação constante desta Revista desde a sua origem.

Refletindo um pouco sobre o tema deste volume, pode-se afirmar que a memória é um elemento fundamental na constituição da identidade. Em síntese, ela é fundamental na construção do discurso, por todas as relações que estabelecemos com o outro. Toda a aprendizagem de uma língua se dá pelo contato com outras pessoas que a praticam; seja na aquisição da língua materna ou de uma segunda língua, as palavras e as estruturas vão sendo adquiridas e armazenadas, construindo a nossa competência discursiva.

Segundo Eclea Bosi, em Memória e Sociedade ${ }^{1}$, ao adotar a diferenciação estabelecida por Bergson, existem dois tipos de memória: a memória-hábito que está nas nossas ações cotidianas derivadas de comportamentos automatizados; e a memória -lembrança, que "se atualiza na imagem-lembrança (...) momento único, singular, não repetido” (1994, p. 48-49). Das relações entre elas, se constrói a competência discursiva. O discurso, de certo modo, medeia nossas relações com o mundo.

Numa breve alusão ao sentido da palavra discurso, dentre muitos, registramos que ele corresponde a um uso particular da língua, em determinado contexto. Esse uso depende de escolhas que o falante faz a partir de um repertório, que fica à sua disposição na memória. É preciso considerar que essas escolhas dependem da intencionalidade e do contexto.

1 BOSI, E. Memória e Sociedade. 7 ed. São Paulo: Companhia das Letras, 1999. 
Linha D’Água (Online), São Paulo, v. 29, n. 1, p. 1-6, jun. 2016

Antes de passarmos à relação com o ensino, trazemos de nossa memória Walter Benjamin que expõe, com uma expressão poética, as relações entre a memória e o discurso em "Escavando e Recordando" (1987, p. 239-240)2:

A língua tem indicado inequivocamente que a memória não é um instrumento para a exploração do passado; é, antes, o meio. É o meio onde se deu a vivência, assim como o solo é o meio no qual as antigas cidades estão soterradas. Quem pretende se aproximar do próprio passado deve agir como o homem que escava. Antes de tudo, não deve temer voltar sempre ao mesmo fato, espalhá-lo como se espalha a terra, revolvê-lo como se revolve o solo. Pois "fatos" nada são além de camadas que apenas à exploração mais cuidadosa entregam aquilo que recompensa a escavação. Ou seja, as imagens que, desprendidas de todas as conexões mais primitivas, ficam como preciosidades nos sóbrios aposentos do nosso entendimento tardio, igual a torsos na galeria do colecionador (...).

Assim, pensamos que estabelecer relações entre memória, discurso e ensino é uma tarefa a que todo aquele que se preocupa com a educação deva dedicar-se. O professor, que é um eterno pesquisador, que traz a experiência, deve explorar esse passado a que se refere Benjamin para participar dessa eterna construção: a memória que nos permite não só guardar fatos, mas presentificá-los com olhos direcionados ao futuro. Assim os textos deste número abordam questões gerais, alguns mais vinculados a aspectos teóricos, outros tratam da prática e do ensino tanto de língua como de literatura e mesmo de aspectos relacionados à legislação, aos PCN (Parâmetros Curriculares Nacionais).

Considerando essas relações, iniciamos a apresentação desse número como o artigo de Sylvie Plane, Os produtores às voltas com o tempo e com a memória, que focaliza as profundas relações entre a escrita, o tempo e a memória. A escrita é um ato praticado individualmente que busca, na memória, informações que ali estão armazenadas. De modo geral, tudo se inscreve num tempo - no anterior e naquele presente -que reconstrói os fatos, as informações pretéritas. Enfatizando as questões das narrativas e valendo-se de observações sobre o tempo em Pouillon (1993, p. 168) e em Ricoeur (1985, p. 230) e, ainda, de estudos sobre a psicologia cognitiva, a autora trabalha com essas conexões entre a temporalidade e a escrita. Para essa abordagem, valeu-se de produções de alunos que registraram várias memórias de uma narrativa, colocando em evidência a memorização de constituintes

2 BENJAMIN, W. Obras Escolhidas.II - Rua de Mão Única. 2 ed. São Paulo: Brasiliense, 1987. 
Linha D'Água (Online), São Paulo, v. 29, n. 1, p. 1-6, jun. 2016

linguísticos. Assim, o artigo faz com que o leitor reflita sobre as complexas relações envolvidas entre a memória, a temporalidade e a escrita.

Uma das preocupações que vem ganhando mais espaço nas discussões sobre o ensino de literatura encontra-se no seu valor não só estético, mas social como formador de cidadãos mais conscientes. Nessa esteira, Vima Lia de Rossi Martin e André de Godoy Bueno propõem, em Por uma memória da África e dos afrodescendentes: aspectos teóricos e legais para o ensino de literaturas africanas e afro-brasileira, uma abordagem pedagógica. De acordo com os autores é necessário que essa proposta se faça num sentido bastante amplo. Como embasamento teórico, utilizam estudos de Antonio Candido (2013), Nelly Novaes Coelho (2000), Regina Zilberman (2008), entre outros. Depois de enfatizarem a importância do ensino da literatura na formação de jovens leitores, discutem a questão central do artigo: "Que literatura ensinar na escola?" Ao buscar uma resposta para o assunto em pauta, voltam-se para a necessidade do ensino das literaturas africanas e afro -brasileira. Tratam da Lei 10.639/03 que prevê que, além da cultura indígena, os alunos, de todos os níveis de ensino no Brasil, estudem história e cultura africana e afro-brasileira, apontam as dificuldades de tal tarefa e deixam claro a necessidade de um trabalho cuidadoso e consciente que aborde a questão de vários ângulos, não se limitando ao cumprimento de uma legislação.

Também, na esteira de uma discussão bastante atual, a da representação social da mulher na literatura, A cantiga medieval como memória histórica da construção social do gênero feminino: reflexóes para o ensino de literatura de Paulo Roberto Sodré e Micheline Mattedi Tomazi trata de como é possível abordar, de modo mais profícuo, a imagem social estereotipada, sexista e patriarcal por meio dos estudos literários. Partindo de uma perspectiva multidisciplinar e crítica, com aporte teórico da proposta sociocognitiva dos Estudos Críticos do Discurso e da Crítica Literária, os autores vão buscar nas cantigas medievais a memória de um discurso e de uma prática social que coloca, ainda no século XXI, a mulher numa posição inferior à do homem. Ao analisar a cantiga medieval de escárnio, os autores propõem-se a resgatar o conhecimento que se produziu em relação às mulheres e poder repensar a posição da mulher por meio de um ensino crítico da literatura. Para Sodré e Tomazi, esse ensino passa por identificar traços linguísticos e vozes que se apresentam nessas cantigas.

Estudando duas figuras de estilo - a metáfora e a metonímia - utilizadas no poema "Água-forte" de Manuel Bandeira, Isabel Cristina Ferreira Teixeira busca, nas lições estruturalistas de Jakobson (1985), compreender como essas figuras constroem a sua expressividade. No artigo Dois aspectos de linguagem e um poema: um estudo estilístico de Agua-forte, ela expõe como procurou construir com alunos 
Linha D'Água (Online), São Paulo, v. 29, n. 1, p. 1-6, jun. 2016

uma reflexão a propósito de como os elementos linguísticos podem constituir a expressividade de um texto. A autora reconhece que as vertentes estruturalistas apresentam limitações uma vez que, para elas, a significação "independe de fatores externos ao próprio sistema”, ou seja, do contexto mais amplo. No entanto, para Teixeira, procedimentos estruturalistas empregados em análises de textos literários podem auxiliar na identificação de qualidades estéticas.

Tendo por base a intertextualidade, um dos elementos que podem ser constitutivos dos textos literários, Guaraciaba Micheletti e Ana Elvira L. Gebara, em Memória literária, leitura e ensino, discorrem, inicialmente, sobre como acreditam que deva ser a leitura na escola e o papel do professor como mediador. Para as autoras, o letramento literário pode se dar a partir de uma leitura e análise com os alunos de textos de diferentes gêneros. Assim, primeiramente registram como uma crônica de jornal - "Cota Zero", de Otto Lara Resende, faz o aproveitamento de toda uma tradição de textos literários e de slogans. Depois, apontam como uma seleção de textos de diferentes épocas, de uma mesma temática, com um enunciador feminino, pode contribuir com a formação de leitores não só de textos literários, mas de quaisquer outros textos - podendo auxiliá-los em tornarem-se leitores proficientes e críticos. As análises baseiam-se em pressupostos teóricos multidisciplinares, mas com uma maior contribuição dos estudos estilísticos.

Tendo em vista a teoria dialógica do discurso e o interacionismo sociodiscursivo, Álvaro Antônio Caretta, em Projetos temáticos no ensino dialógico-discursivo da lingua portuguesa, procura demonstrar, a importante contribuição dos projetos temáticos para o ensino da língua portuguesa. Partindo da concepção dialógica da linguagem, proposta por Bakhtin, o autor enfatiza "a importância de se trabalhar com os variados gêneros discursivos - orais, escritos e multimodais -, nos diversos eixos didáticos - leitura, oralidade, produção textual e análise linguística -, valorizando a interação social". Carreta destaca, ainda, a importância de se trabalhar os multiletramentos e, referindo-se aos PCN (Parâmetros Curriculares Nacionais), aponta a relevância de projetos para uma formação mais consistente dos alunos, formação que thes permita uma verdadeira atuação social.

A contribuição de Clécio Bunzen e Rejane R. Almeida de Medeiros com O ensino de gramática na Primeira República (1889-1930): uma análise da Gramática Expositiva, de Eduardo Carlos Pereira diz respeito à memória histórica, detendose no ensino da Gramática entre o final do século XIX e as primeiras décadas do século XX. Os autores buscam entender como a disciplina Português adquiriu um crescente espaço no currículo humanista do ensino secundário. Clécio e Rejane analisam a situação do ensino gramatical nesse período, observando que os estudos estavam voltados para uma gramática expositiva e obedeciam a uma norma única, 
Linha D'Água (Online), São Paulo, v. 29, n. 1, p. 1-6, jun. 2016

construída em torno de excertos de autores brasileiros e, especialmente, portugueses. Os autores, ainda, dedicam-se à obra de Eduardo Carlos Pereira que se constitui em um marco do ensino gramatical no Brasil.

Observando que a memória é o espaço da construção da identidade e do sentimento de pertencimento, Norma Seltzer Goldstein e Francesco Antonio Capo, em Escritas da memória: autoria e identidade cultural, discorrem sobre como as representações do passado e do presente são perpassadas por representações construídas social e historicamente. Assim, tendo por objetivo um trabalho com o letramento de adultos, observam como a memória exerce um papel bastante significativo na apropriação da escrita. Os autores salientam que uma das maiores dificuldades em lidar com os estudantes do EJA (Educação de Jovens e Adultos) reside na diversidade de contextos culturais de que eles provêm. Para Goldstein e Capo, uma das formas de resolver essa dificuldade pode estar na recuperação, por meio da narrativa de variadas experiências, ou seja, recobrando pela memória as vivências individuais e socializando-as para que o letramento seja possível numa atmosfera mais amigável.

$\mathrm{Na}$ perspectiva de um ensino mais aberto e integrado às novas tecnologias, este número inclui o artigo de Rosalice Botelho Pinto, Empreendedorismo e ramifcação no desenvolvimento profissional, em que a autora analisa o papel dos serious games na formação de competências empreendedoras. Pinto, inicialmente, apresenta e elucida termos próprios do mundo da informatização, discorrendo sobre como, a partir de 1990, houve um grande desenvolvimento do e-lerning. Trata, ainda, enfatizando a necessidade da revisão metodológica do ensino por meio de novas tecnologias -, de conceitos do ponto de vista teórico e aponta como certos suportes se democratizaram, assinalando que a informática adquire um papel primordial na vida das pessoas e no mundo do trabalho.

Preocupada com a prática pedagógica no que concerne ao ensino da escrita, Silvia Augusta de Barros Albert, em Coesão, coerência e construção de objetos de discurso: vislumbrando uma perspectiva sociocognitiva e interacional para o ensino da produção escrita, tece considerações sobre como os elementos de coesão, coerência e referenciação podem ser instrumentos para uma aprendizagem mais eficaz da escrita. Trabalhando com um corpus constituído por redações de vestibulares, Sí1via propõe algumas possibilidades de intervenção que, considerando os aspectos sociais da escrita, podem conduzir os estudantes à realização de textos não só mais coesos e coerentes, mas mais adequados aos propósitos interacionais.

Com o objetivo de trabalhar a leitura (crítica) em sala de aula, Lília Santos Abreu-Tardelli, Andressa Cristiane dos Santos, Letícia Fonseca Borges e Natália Santos Ciceri detêm-se no discurso de Dilma Rousseff na abertura da $68^{\circ}$ 
Linha D'Água (Online), São Paulo, v. 29, n. 1, p. 1-6, jun. 2016

Assembleia-Geral da ONU e estabelecem relações com a charge política eletrônica, analisando-os comparativamente, a partir do apoio teórico especialmente de Bronckart (1999), Ducrot (1987) e Koch (1999), esclarecerem, em O discurso politico e a charge eletrônica: uma análise à luz do interacionismo sociodiscursivo, como se manifestam as vozes que se fazem representadas. Elas apontam a relação dialógica entre os textos e ressaltam os mecanismos enunciativos (vozes e modalizações). Ao ressaltar os mecanismos enunciativos, as autoras fazem com que os leitores se apropriem de conhecimentos que lhes permitem uma interpretação mais profunda do discurso verbal e daquele da charge eletrônica.

Finalizando a sequência de artigos o volume traz o Discurso sobre ensino de língua portuguesa na universidade: as (des)construçôes do imaginário de ensino de língua em graduação de direito, de Mary Neiva Surdi da Luz e Rossaly Beatriz Chioquetta Lorenset. Ao examinar o corpus selecionado, as autoras identificaram "ecos e ressonâncias do imaginário de língua da historicidade do ensino de língua e da constituição do Ensino Superior no Brasil, de mais de dois séculos". E, de acordo com Luz e Lorenset, voltando os olhos para o passado, é possível notar como foi construído o imaginário da língua jurídica, com marcas de uma retórica persuasiva e de boa argumentação.

Encerrando o volume, encontra-se uma resenha de Mireille Froment sobre Points de vue sur le point de vue, de Marie Carcassonne, Dóris Cunha, Christiane Donahue, Frédéric François et Alain Rabatel. Como o título enuncia, cada um dos autores busca apontar como se constroem os pontos de vista dos receptores. Conforme Mireille Froment, na tradução de Dóris de Arruda C. da Cunha, os autores se detém em gêneros textuais e nas significações que "são desenhadas" nos textos, apresentando uma diversidade de perspectivas, ainda que tenham em comum algumas opções teóricas. É uma resenha que instiga o seu leitor a conhecer a obra de que trata.

A tarefa de redigir um editorial é sempre um desafio, já que o editorialista lança seu olhar sobre vários textos, tenta, vivenciado cada um deles, extrair-lhes aquilo que lhe parece ser o cerne e recorre à sua memória para construir o seu texto na expectativa de poder, além de informar, despertar nos seus leitores o desejo de lê-los e também participar da experiência para a qual eles nos convidam.

Junho 2016 